\title{
Age and Gender Distribution of Benign Breast Lesions of Women at Port City of Bangladesh
}

\author{
Nazmun Nahar ${ }^{1}$, Mohammed Iqbal ${ }^{2}$, Kazi Md. Shahidur Rahman ${ }^{3}$, Sabrina Razzaque ${ }^{4}$, Farida Yeasmin ${ }^{5}$, \\ Urmee Alam $^{6}$, Md. Abbas Uddin ${ }^{7}$
}

\begin{abstract}
Background: Benign breast diseases are the most common cause of breast problems. The most common symptoms are breast pain, lumpiness or a lump and nipple discharge. Triple assessment that includes clinical examination, imaging like ultrasonography (USG) or mammography and a pathological examination - FNAC or core needle biopsy has a very high accuracy rate in diagnosing, discrete benign breast diseases and this can be used for reassurance. Objective: The purpose of the present study was to determine the frequency of different types of benign neoplasm of breast lump in different age and sex. Methodology: The present study was carried out at the Department of Pathology, Chittagong Medical College, Bangladesh one year period from May 2005 to June 2006. This study was cross sectional which included 48 cases of breast neoplasm. The specimens were received from indoor patient Department of Surgery, Chittagong Medical College, Bangladesh. Histopathological examination was done. Results: This study shows the mean age of the patients was 32.91 years with age range 11 to 70 years. Most of the patients were in 31 to 50 years $(45.8 \%)$ age group and female predominance than male. Fibroadenoma accounted for $76.2 \%$. Sclerosing adenosine the second most common benign breast disease in this study accounted for $9.5 \%$ of cases. Conclusion: This study showed that among the benign breast diseases in females there were preponderance of fibroadenoma followed by sclerosing adenosine. [Journal of Science Foundation 2018;16(1):27-31]
\end{abstract}

Keywords: Age; Gender; Benign Breast Lesions; Women; Port City of Bangladesh [Reviewed: 30 October 2017; Accepted on: 1 December 2017; Published on: 1 January 2018]

\footnotetext{
${ }^{1}$ Associate Professor \& Head, Department of Pathology, Medical College for Women \& Hospital, Uttara, Dhaka, Bangladesh

${ }^{2}$ Associate Professor. Department of Anatomy, Monno Medical College, Manikganj, Bangladesh

${ }^{3}$ Assistant Professor, Department of Pathology, Monno Medical College, Manikgonj, Bangladesh

${ }^{4}$ Associate Professor, Department of Pathology, Medical College for Women \& Hospital, Uttara, Dhaka, Bangladesh

${ }^{5}$ Associate Professor, Department of Anatomy, Tairunnesa Memorial Medical College, Gazipur, Bangladesh

${ }^{6}$ Assistant Professor, Department of Gynaecology \& Obstetrics, USTC, Chittagong, Bangladesh

${ }^{7}$ Associate Professor \& Head, Department of ENT, BGC Trust Medical College, Chittagong, Bangladesh
}

Correspondence: Dr. Nazmun Nahar, Associate Professor \& Head, Department of Pathology, Medical College for Women \& Hospital, Uttara, Dhaka, Bangladesh; Cell no.: +8801914140697; Email: iqbal085nahar082@ gmail.com 


\section{Introduction}

Breast tissue in females is under the influence of various hormones and is subjected to constant physiological variations throughout the reproductive live and beyond. This leads to different clinical manifestations and diseases (Mahmood et al., 2003). The presence of a lump in the breast is a great cause of anxiety, apprehension and uncertainty to most patients. This may be accrued to the increasing public awareness of breast cancer which is presently the most common female malignancy worldwide (Lester 2015). Nevertheless, the vast majority of breast lesions are benign (Kumar 2010; Jamal 2001). Benign breast diseases (BBD), however, constitute a heterogeneous group of disorders range from developmental abnormalities, inflammatory lesions, epithelial and stromal proliferations to various neoplasms. They may present a wide range of symptoms or may be detected as incidental microscopic findings (Guray and Sahin 2006). BBD can present as a palpable mass, pain, and nipple discharge or nipple inversion.

It is impossible to know whether a breast lump is cancerous without performing imaging examinations and/or a biopsy and/or Fine-needle aspiration cytology (FNAC). FNAC is a part of the triple assessment for the diagnosis of breast lesions. It is an established, highly accurate method for diagnosing breast cancer and has given rise to a reduction in the number of excision biopsies for benign breast disease (Mottahedeh et al., 2003), but excisional biopsy remains the gold standard for diagnosis (Kumar 2010).

It is important for pathologists, radiologists, and oncologists to recognize benign lesions, both to distinguish them from in situ and invasive breast cancer and to assess a patient's risk of developing breast cancer, so that the most appropriate treatment modality for each case can be established. In Bangladesh, the data available regarding the pattern of various benign breast lesions is limited. Most studies have found on malignant breast diseases. This study was undertaken to determine the frequency of different types of benign neoplasm of breast lump in different age and sex.

\section{Methodology}

The present study was carried out at the Department of Pathology at Chittagong Medical College, Chittagong, Bangladesh for one year period from May 2005 to June 2006. This study was cross sectional which included 48 cases of breast neoplasm. The specimens were received from indoor patient Department of Surgery at Chittagong Medical College, Chittagong, Bangladesh. The patient presents with definite palpable breast lump, irrespective of age and sex were included in this study. A total number of 48 cases of specimens of paraffin embedded tissue were sectioned and stained with hematoxylin and eosin. All tissue were study histopathologically and all data were statistically evaluated in SPSS version 17.

\section{Result}

A total number of 48 cases of specimens of paraffin embedded tissue were sectioned and stained with hematoxylin and eosin.

Table 1: Distribution of the 48 patients according to age

\begin{tabular}{|l|c|c|}
\hline Age Group & Frequency & Percentage \\
\hline 11 to 20 Years & 10 & 20.9 \\
\hline 21 to 30 Years & 9 & 18.8 \\
\hline 31-40 Years & 11 & 22.9 \\
\hline 41-50 Years & 11 & 22.9 \\
\hline 51-60 Years & 4 & 8.3 \\
\hline 61-70 Years & 3 & 6.2 \\
\hline Total & $\mathbf{4 8}$ & $\mathbf{1 0 0 . 0}$ \\
\hline Mean \pm SD & \multicolumn{2}{|c|}{$32.91 \pm 12.94$} \\
\hline
\end{tabular}

Table 1 shows maximum (45.8\%) were 31 to 50 years. The average age was $32.91 \pm 12.94$ years. 
Table 2: Distribution of Breast Lesion of the 48 patients according to Sex

\begin{tabular}{|l|c|c|l|}
\hline \multirow{2}{*}{ Gender } & \multicolumn{2}{|c|}{ Types of Neoplasm } & \multirow{2}{*}{ Total } \\
\cline { 2 - 3 } & Benign & Malignant & \\
\hline Female & $21(43.8 \%)$ & $26(54.2 \%)$ & $47(97.9 \%)$ \\
\hline Male & $0(0 \%)$ & $1(2.1 \%)$ & $1(2.1 \%)$ \\
\hline Total & $\mathbf{2 1}$ & $\mathbf{2 7}$ & $\mathbf{4 8}$ \\
\hline
\end{tabular}

Table 2 shows maximum patients were female both benign (43.8\%) and malignant (54.2\%).

Table 3: Association between age group with benign and malignant neoplasm of $\mathbf{4 8}$ breast lump

\begin{tabular}{|l|c|c|l|l|}
\hline \multirow{2}{*}{ Age group } & \multicolumn{2}{|c|}{ Type of Neoplasm } & \multirow{2}{*}{ Total } & \multirow{2}{*}{ p value } \\
\cline { 2 - 3 } & Benign & Malignant & & \\
\hline 11 to 20 Years & $9(42.9 \%)$ & $0(0.0 \%)$ & $9(18.8 \%)$ & \\
\hline 21 to 30 Years & $5(23.8 \%)$ & $5(18.5 \%)$ & $10(20.8 \%)$ & \\
\hline 31 to 40 Years & $5(23.8 \%)$ & $6(22.2 \%)$ & $11(22.9 \%)$ & \multirow{2}{*}{0.001} \\
\hline 41 to 50 Years & $2(9.5 \%)$ & $9(33.3 \%)$ & $1122.9 \%)$ & \\
\hline 51 to 60 Years & $0(0.0 \%)$ & $4(14.8 \%)$ & $4(8.3 \%)$ & \\
\hline 61 to 70 Years & $0(0.0 \%)$ & $3(11.1 \%)$ & $3(6.2 \%)$ & \\
\hline Total & $21(100.0 \%)$ & $27(100.0 \%)$ & $48(100.0 \%)$ & \\
\hline
\end{tabular}

Table 3 shows highest percentage of benign neoplasm were age group 11-20 years (42.9\%). On the other hand, in malignant neoplasm highest percentage of age group 41-50 years (42.9\%).

Table 4: Histopathological categories of benign Cases in different age groups $(n=21)$

\begin{tabular}{|c|c|c|c|c|c|c|c|}
\hline \multirow[b]{2}{*}{$\begin{array}{c}\text { Histopathological } \\
\text { diagnosis }\end{array}$} & \multicolumn{6}{|c|}{ Age in years } & \multirow[b]{2}{*}{$\begin{array}{c}\text { Total } \\
21(100 \%)\end{array}$} \\
\hline & $\stackrel{\text { I }}{=}$ & $\stackrel{\text { }}{\grave{n}}$ & $\underset{P}{\stackrel{P}{i}}$ & 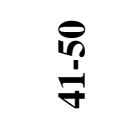 & $\frac{8}{1}$ & $\frac{1}{6}$ & \\
\hline Fibroadenoma (FA) & $8(38.1)$ & $3(14.3)$ & $3(14.3)$ & $2(9.5)$ & $0(0.0)$ & $0(0.0)$ & $16(76.2)$ \\
\hline $\begin{array}{l}\text { Fibrocystic change } \\
\text { (FCC) }\end{array}$ & $0(0.0)$ & $1(4.8)$ & $0(0.0)$ & $0(0.0)$ & $0(0.0)$ & $0(0.0)$ & $1(4.8)$ \\
\hline $\begin{array}{l}\text { Benign Cystic } \\
\text { Lesion (BCL) }\end{array}$ & $0(0.0)$ & $0(0.0)$ & $1(4.8)$ & $0(0.0)$ & $0(0.0)$ & $0(0.0)$ & $1(4.8)$ \\
\hline $\begin{array}{l}\text { Sclerosing } \\
\text { Adenosis (SA) }\end{array}$ & $0(0.0)$ & $1(4.8)$ & $1(4.8)$ & $0(0.0)$ & $0(0.0)$ & $0(0.0)$ & $2(9.5)$ \\
\hline $\begin{array}{l}\text { Benign Fibrous } \\
\text { Histiocytoma } \\
(\mathrm{BPh})\end{array}$ & $1(4.8)$ & $0(0.0)$ & $0(0.0)$ & $0(0.0)$ & $0(0.0)$ & $0(0.0)$ & $1(4.8)$ \\
\hline
\end{tabular}

Table 4 show the age group distribution of the various histological types of benign cases. Highest percentage of Fibroadenoma (FA) were age group 11-20 years. Others depicted in tables 4.

\section{Discussion}

For correct diagnosis of breast disease background knowledge of general features of individual breast disease like incidence, age distribution, symptoms and palpatory findings are very important. There is a wide spectrum of clinical conditions both benign and malignant which affect the breast from teen age to throughout adult life. The incidence of these presentations varies in different geographical areas according to the spectrum of the breast diseases encountered. Overall, breast problems are commonly seen in females as 
compared to males (Amin 2009; Al-Nazer 2004; Hussain et al., 2005). Similarly, in this study females were more affected than males.

The mean age of the patients was 34.87 years with age range 13 to 67 years. Most of the patients were in 1120 years (42.9\%) age group, as reported in other studies (Jensen et al., 1989; Adesunkanmi and Agbakwuru 2001). Another study found majority patients in 31 to 40 years age group (Kathcy et al., 1990). This agrees with many reports (Amin 2009; Adeniji et al., 1997).

Previous reports indicate that the incidence of BBD far outnumber that of breast cancer. In Enugu, Kano, Calalar, and Ibadan, BBD accounted for $68.8 \%, 73 \%, 73.4 \%$, and $89.4 \%$ of all breast lumps respectively (Mottahedeh et al., 2003). This was also our observation. In this study, BBDs accounted for $43.8 \%$ of all breast lesions.

Fibroadenoma was the most common BBD in this study accounting for $76.2 \%$ of cases. This was also the finding in most previous studies done in Nigeria. In Ilesha, Enugu, Port Harcourt, and Ife, fibroadenoma accounted for $46.2 \%, 44.0 \%, 51.0 \%$, and $59.1 \%$ of cases of BBD respectively (Kumar 2010; Mottahedeh et al., 2003; Adeniji et al., 1997). Fibroadenoma was also the commonest BBD in Ghana and USA accounting for 70 and 48\% of BBDs respectively (Bewtra 2009; Oluwole and Freeman 1979). However, in Kano, fibroadenoma was documented as the second commonest BBD comprising $28.8 \%$ of cases, a finding consistent with reports from Pakistan and Jamaica where fibroadenoma accounted for 29.4, 33\% respectively (Memon et al., 2007; Shirley et al., 2008). A racial predilection of Negroes to fibroadenoma has however, been previously documented (Oluwole and Freeman 1979). This may account for the higher frequency of fibroadenoma in this and other African studies. This increased frequency may be modulated by genetic, environmental and socio-cultural factors.

Sclerosing adenosis the second most common BBD in this study, accounted for 9.5\%. Sclerosing adenosis has been classified as a proliferative lesion without atypia, having a relative risk of 1.3-1.9 for invasive carcinoma (Jensen et al., 1989). Sclerosing adenosis, a lobulocentric lesion of disordered acini, myoepithelial, and connective tissues, may be difficult to distinguish grossly from infiltrating carcinoma and may occur in association with other epithelial hyperplasia including epithelial hyperplasia and intraductal papilloma. It may also coexist with invasive and in situ carcinoma (Cheng et al., 2008).

Fibrocystic change lesion accounted for $(4.8 \%)$ of the cases in this study. Fibrocystic change of cases, a figure inconsistent with the 22.9 and $27.7 \%$ documented in Enugu and Port Harcourt respectively (Kumar 2010). A much higher figure of $42.2 \%$ was however reported in Ilesha and of note, fibrocystic change was reported as the commonest BBD in Kano comprising 34.3\% of cases (Jamal 2001; Adesunkanmi and Agbakwuru 2001). In Italy and in another study in the USA, fibrocystic change was also the commonest BBD accounting for 43.2 and 47\% of cases respectively (Ciatto et al., 1998; Donegan and Spratt 1995). Fibrocystic change seems relatively more common in Pakistanis as Memmon et al (2007) reported a high frequency of $66.3 \%$ and observed a changing trend of benign tumors from fibroadenoma to fibrocystic change.

Fibrocystic change consists of a spectrum of morphological changes comprising cysts, adenosis epithelial hyperplasia, and fibrosis and occurs predominantly between the ages of 30 and 50 years (Ciatto et al., 1998; Donegan and Spratt 1995). The age range of patients with fibrocystic change in this study was 13 to 76 years, with a mean age of 30 years which is in consonance with the 32, 33, and 37 years documented in Ibadan, Kano, and Ife, respectively (Jamal 2001; Adeniji et al., 1997). Though both fibroadenoma and fibrocystic disease had a peak occurrence in the third decade, in contrast to fibrocystic disease which showed a relatively high prevalence up to the fifth decade, a sharp decline in the occurrence of fibroadenoma was observed after the third decade.

\section{Conclusion}

This study shows Fibroadenoma is the commonest of all followed by Sclerosing adenosis. Breast self examination and health education to females is very important in cases of benign proliferative lesions. Histopathology plays an important role in the diagnosis of benign breast diseases. When correlated with 
clinical data, mammographic findings, breast ultrasonography and extensive use of fine needle aspiration cytology, the histopathological examination led to the early diagnosis of a benign breast disease.

\section{Reference}

Adeniji KA, Adelusola KA, Odesanmi WO. Benign disease of the breast in Ile-Ife: A 10 year experience and literature review. Cent Afr J Med. 1997;43:140-3

Adesunkanmi AR, Agbakwuru EA. Benign breast lesions in Wesley Guild Hospital, Ilesha, Nigeria. West Afr J Med 2001;20:146-51 Al-Nazer MA. Outline of breast diseases in Qatif Central Hospital. Kuwait Medical Journal 2004; 36(3): 182-185.

Amin TT. Histopathological patterns and risk of female breast lesions at a secondary level of care in Saudi Arabia. Asian Pacific J Cancer Prev 2009; 10: 1121-1126

Bewtra C. Fibroadenoma in women in Ghana. Pan Afri Med J. 2009;2:11

Cheng J, Qiu S, Raju U, Wolman SR, Worsham MJ. Benign breast disease heterogeneity: Association with histopathology, age and ethnicithy. Breast Cancer Res Treat. 2008;111:289-96

Ciatto S, Bonardi R, Ravaioli A, Canuti D, Foglietta F, Modena S, et al. Benign breast disease surgical biopsies, are they always justified? Tumori. 1998;84:521-4

Donegan WL, Spratt JS. Cancer of the breast. 4th ed. Vol. 9. Philadelphia: Saunders WB; 1995. Cancer Prev; pp. 1-15

Guray M, Sahin AA. Benign breast diseases - classification, diagnosis and management. Oncologist 2006; 11(5): 435-449

Hussain N, Ayaz B, Nadia N, Ali Z. Pattern of female breast diseases in Karachi. Biomedica 2005; 21: 36-38

Jamal AA. Pattern of breast diseases in a teaching hospital in Jeddah, Saudi Arabia. Saudi Med J 2001; 22(2): 110-113

Jensen RA, Page DL, Dupont WD, Rogers LW. Invasive breast cancer risk in women with sclerosing adenosis. Cancer. 1989;64:1977-83

Kathcy KC, Datubo-Brown DD, Gogo-Abite M, Iweha UU. Benign breast lesions in Nigerian women in Rivers State. East Afr Med J. 1990;67:201-4

Kumar R. A clinicopathologic study of breast lumps in Bhairahwa, Nepal. Asian Pacific J Cancer Prev 2010; 11: 855-858

Lester SC. The Breast. In: Robbins and Cotran Pathologic basis of disease. $9^{\text {th }}$ edn. Philadelphia: Elsevier Saunders, 2015; 1043-1071

Mahmood A, Ahmed M, Jamal S. Role of cytological grading in the management of breast lump. J Coll Pysicians Surg Pak 2003; 13(3): 150-152.

Memon A, Parveen S, Sangrarasi AK, Malik AM, Laghari A. Changing pattern of benign breast lumps in young females. World J Med Sci. 2007;2:21-4.

Mottahedeh M, Rashid MH, Gateley CA. Final diagnoses following C3 (atypical, probably benign) breast cytology. Breast 2003; 12(4): 276-279.

Oluwole SF, Freeman HP. Analysis of benign breast lesions in blacks. Am J Surg. 1979;137:786-9

Shirley SE, Mitchell DI, Soares DP, James M, Escoffery CT, Rhoden AM, et al. Clinicopathologic features of breast disease in Jamaica: Findings of the Jamaican Breast Disease Study, 2000-2002. West Indian Med J. 2008;57:90-4 